\title{
Entamoeba histolytica como causa de diarreia crônica
}

\section{Entamoeba histolytica as a cause of chronic diarrhea}

\section{Entamoeba histolytica como causa de diarrea crónica}

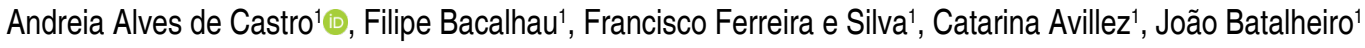 \\ ${ }^{1}$ Unidade de Saúde Familiar Amora Saudável. Amora, Portugal.
}

\section{Resumo}

A diarreia crônica, caracterizada pela presença de mais de três dejeções de consistência pastosa durante pelo menos quatro semanas, é frequentemente encontrada na prática clínica. Na diarreia crônica, a probabilidade de uma etiologia infecciosa é baixa, sendo as causas funcionais, inflamatórias, osmóticas ou secretórias mais comuns. A amebíase intestinal é uma causa de diarreia crônica, causada pelo protozoário Entamoeba histolytica, sendo comum e prevalente em países em desenvolvimento. Pode ter várias formas de apresentação, sendo na maioria dos casos assintomática. Apresenta-se o caso clínico de um paciente de 27 anos, sexo masculino, raça caucasiana, homem que pratica sexo com homens $(\mathrm{HSH})$, com diarreia crônica com início há cerca de seis anos. $O$ exame objetivo não revelava alterações. Realizou exame parasitológico de fezes, com isolamento de quistos de Entamoeba histolytica. Foi medicado com metronidazol e paromomicina com resolução clínica do quadro. É importante para o Médico de Família equacionar esta etiologia na investigação de pacientes com diarreia, para um correto e atempado diagnóstico e tratamento, de modo a evitar exames desnecessários, possíveis complicações, a transmissão do agente e um grave problema de saúde pública.

Palavras-chave: Diarreia; Entamoeba histolytica; Disenteria Amebiana; Saúde Pública

\begin{abstract}
Chronic diarrhea, characterized by the presence of more than three loose stools for at least four weeks, is often found in clinical practice. In chronic diarrhea, the probability of an infectious etiology is low, having usually a functional, inflammatory, osmotic or secretory origin. Intestinal amebiasis is a cause of chronic diarrhea, caused by the protozoan Entamoeba histolytica, common and prevalent in developing countries. It can have different presentations but most patients are asymptomatic. We present a 27-year-old Caucasian male, man who have sex with men (MSM), with chronic diarrhea starting six years ago. The physical exam was normal. A parasitological stool examination was performed with isolation of cysts of Entamoeba histolytica. He was treated with metronidazole and paromomycin with clinical resolution. It is important for General Practice to address this etiology in the investigation of patients with diarrhea for a correct and timely diagnosis and treatment, to avoid unnecessary testing, possible complications, transmission of the agent and a serious public health problem.
\end{abstract}

Keywords: Diarrhea; Entamoeba histolytica; Dysentery, Amebic; Public Health

Como citar: Castro AA, Bacalhau F, Silva FF, Avillez C, Batalheiro J. Entamoeba histolytica como causa de diarreia crônica. Rev Bras Med Fam Comunidade. 2019;14(41):1917. https://doi.org/10.5712/rbmfc14(41)1917

\author{
Autor correspondente: \\ Andreia Alves de Castro. \\ E-mail: andreiapatricia.castro@gmail.com \\ Fonte de financiamento: \\ declaram não haver. \\ Parecer CEP: \\ não se aplica. \\ Procedência e revisão por pares: \\ revisado por pares. \\ Recebido em: 10/11/2018. \\ Aprovado em: 28/02/2019 .
}




\section{Resumen}

La diarrea crónica, caracterizada por la presencia de más de tres heces de consistencia blanda durante al menos cuatro semanas, es frecuentemente encontrada en la práctica clínica. En la diarrea crónica, la probabilidad de una etiología infecciosa es baja, siendo las causas funcionales, inflamatorias, osmóticas o secretoras más comunes. La amebiasis intestinal es una causa de diarrea crónica, causada por el protozoario Entamoeba histolytica, siendo común y prevalente en los países en desarrollo. Puede tener varias formas de presentación, siendo en la mayoría de los casos asintomática. Presentamos un paciente de 27 años, sexo masculino, caucásico, hombre que tiene sexo con hombres (HSH), con diarrea crónica con inicio hace cerca de seis años. El examen objetivo no reveló alteraciones. Realizó un examen parasitológico de heces, con aislamiento de quistes de Entamoeba histolytica. Fue medicado con metronidazol y paromomicina con resolución clínica del cuadro. Es importante para el médico de familia considerar esta etiología en la investigación de pacientes con diarrea, para un correcto y oportuno diagnóstico y tratamiento, de modo a evitar, exámenes innecesarios, posibles complicaciones, la transmisión del agente y un grave problema de salud pública.

Palabras clave: Diarrea; Entamoeba histolytica; Disentería Amebiana; Salud Pública

\section{Introdução}

A diarreia crônica caracteriza-se pela presença diária de três ou mais dejeções pastosas ou aquosas durante pelo menos quatro semanas. É uma afecção relativamente comum que afeta cerca de $5 \%$ da população em países desenvolvidos e, apesar da causa mais comum nesses países ser a síndrome de Intestino Irritável (SII), o seu diagnóstico diferencial ainda representa um desafio. ${ }^{1}$

A diarreia pode dividir-se em três tipos: aquosa, esteatorreica e inflamatória. A diarreia aquosa é subdividida em osmótica, secretora e funcional, sendo a SII a causa mais comum de diarreia crônica funcional. $^{2}$

Em países em desenvolvimento, a diarreia crônica é frequentemente causada por infecções crônicas bacterianas, micobacterianas ou parasitárias, na qual se inclui a amebíase intestinal. ${ }^{1}$

A amebíase intestinal é uma causa orgânica de diarreia crônica do tipo secretora, sendo uma doença comum e prevalente em países em desenvolvimento, causada por um protozoário, Entamoeba histolytica. ${ }^{3}$

Foi descrita pela primeira vez em 1875 por Lösch, após observação de trofozoítos nas fezes de pacientes com disenteria. ${ }^{4}$

Segundo a Global Burden of Disease Study de 2013, as infecções intestinais causadas por protozoário são consideradas a terceira causa de morte a nível mundial, resultando em mais de 100.000 mortes anualmente. ${ }^{5}$ Atualmente, pensa-se que estes números estejam sobrestimados em resultado da difícil diferenciação microscópica entre $E$. histolytica e outros dois parasitas (E. dispar e E. moshkovskii), sendo a $E$. histolytica a única espécie reconhecida como patógeno humano e a $E$. dispar dez vezes mais prevalente. ${ }^{4}$

A sua distribuição é mundial e é frequentemente diagnosticada em imigrantes e viajantes de áreas endêmicas (nomeadamente Índia, África, México e zonas da América Central e do Sul). ${ }^{3,5}$

Até o ano de 1999, era considerada uma doença de declaração obrigatória em Portugal e os últimos dados publicados (referentes ao período de 1992-1996) reportaram uma taxa de incidência mediana de 0,04 casos/milhão de habitantes. ${ }^{6}$

A transmissão dá-se por ingestão de alimentos e água contaminada ou via sexual (fecal-oral). ${ }^{3,5} \mathrm{Em}$ países desenvolvidos, onde o risco de transmissão de Entamoeba histolytica por contaminação alimentar é baixo, foi demonstrada uma prevalência de amebíase superior à esperada em homens que fazem sexo 
com homens. A prática de sexo oral e anal e a elevada promiscuidade condicionam o aumento do número de casos neste grupo e a consequente contaminação dos parceiros sexuais e contatos próximos. ${ }^{3}$

O período de incubação é variável, desde dias a meses ou anos (em média de 2 a 4 semanas). ${ }^{7}$

A apresentação clínica pode ir desde portador assintomático até um quadro de colite fulminante com perfuração intestinal e peritonite, necrose do cólon ou megacólon tóxico. . $^{3,8}$ Apenas 10-20\% destes portadores desenvolvem manifestações clínicas da doença. ${ }^{3}$

Pode ser diagnosticado através da identificação do parasita nas fezes ou teste serológico do antígeno (sensibilidade $87 \%$ e especificidade $>90 \%$, valores superiores ao exame parasitológico). ${ }^{7}$

Os portadores, sintomáticos ou não, devem ser tratados devido ao risco aumentado de desenvolver e transmitir a doença. ${ }^{3}$

\section{Detalhamento do caso}

Sexo masculino, 27 anos, raça caucasiana, homem que pratica sexo com homens, médico, natural de Santarém e residente em Lisboa (Portugal) em habitação com boas condições sanitárias, no estádio I do Ciclo de Vida Familiar de Duvall (casal sem filhos). Sem antecedentes pessoais. Sem antecedentes familiares para afecção gastrointestinal. Sem alergias conhecidas e sem medicação habitual. Ex-fumante de 10 unidades maço ano. Hábitos etílicos esporádicos. Sem hábito de consumo de drogas. História de viagens a países em desenvolvimento (México, Tailândia e Camboja).

Foi observado em 2012 em consulta de Gastroenterologia por um quadro de diarreia com cerca de seis meses de evolução, associado a dor abdominal tipo cólica e flatulência, tendo sido colocadas como hipóteses diagnósticas: síndrome do Cólon Irritável e doença Inflamatória Intestinal (DII). Realizou tomografia computorizada abdominal, que não revelou alterações significativas, e um Clister opaco que evidenciou uma diverticulose intestinal e um dolicocólon. Iniciou uma dieta com evicção de produtos com lactose e, dada uma discreta melhoria sintomática, foi considerado como diagnóstico principal intolerância à lactose.

Apesar de se manter sintomático, o paciente ficou sem seguimento até julho de 2018 , devido ao reduzido impacto das queixas no dia-a-dia, sendo nesta altura observado em consulta programada com o Médico de Família após integração numa recém-formada lista de utentes. O paciente apresentava episódios semanais de dejeções pastosas com 2 a 3 dias de duração ( 3 a 4 dejeções diárias, de coloração normal, sem sangue ou muco nas fezes). Negava dor abdominal, flatulência, distensão abdominal, alterações cutâneas, intolerâncias alimentares documentadas ou alterações articulares.

Ao exame objetivo, encontrava-se corado, hidratado e apirético. Sem alterações cutâneas, nomeadamente sinais de discrasia hemorrágica. Apresentava um ligeiro desconforto à palpação profunda da fossa ilíaca direita, sem outras alterações relevantes. Foram pedidas coproculturas que resultaram negativas, e pedido um exame parasitológico de fezes que revelou a presença de quistos de Entamoeba histolytica.

Foi referenciado à consulta de Infecciologia do hospital de referência para instituição de terapêutica farmacológica adequada. Foi medicado com metronidazol $750 \mathrm{mg}$ por via oral 3 vezes por dia durante 10 dias, seguido de paromomicina $750 \mathrm{mg}$ por via oral 3 vezes por dia durante 7 dias. 
Foram abordadas na consulta algumas medidas como o uso de preservativo em qualquer prática sexual e a abstinência sexual durante o período de tratamento, para prevenção de doenças sexualmente transmissíveis e o contágio, respectivamente; assim como a importância de boas práticas de higiene em viagem a países endêmicos, como beber apenas água engarrafada, cozinhar os alimentos e não ingerir fruta sem casca.

Foi pedida avaliação serológica para o vírus da imunodeficiência humana (HIV), sífilis e hepatite B, com o consentimento do paciente, que resultou negativa.

Foi também informado da importância de agendar consulta perante um sintoma que se manifesta de forma crônica.

O atual parceiro e os contatos próximos foram avaliados e estudados para o despiste de infecção, tendo-se excluído a mesma.

O paciente tem mantido a vigilância em consulta de rotina encontrando-se, até à data, assintomático.

\section{Discussão}

A diarreia crônica, apesar de não ser um motivo frequente de consulta nos cuidados de saúde primários, é um sintoma importante, podendo revelar apenas uma alteração funcional ou ser a manifestação clínica de uma afecção grave.

A amebíase é uma causa maior de morbimortalidade em todo o mundo, majoritariamente em países tropicais e subtropicais, onde é mais prevalente, caracterizados por uma difícil acessibilidade aos serviços de saúde e existência de infraestruturas sanitárias inadequadas. ${ }^{3}$

A prevalência da infecção por Entamoeba histolytica pode alcançar os $50 \%$ em áreas da América Central e do Sul, África e Ásia. ${ }^{7}$ No Brasil, a distribuição epidemiológica da amebíase permanece desconhecida em várias áreas geográficas, sendo a sua prevalência, patogenicidade e virulência variáveis nas diferentes regiões. A infecção por Entamoeba histolytica é mais comum no Norte e Nordeste do país, com prevalências entre os $6,8 \%$ e $29,35 \% .^{9}$

Apesar das parasitoses serem uma causa incomum de diarreia crônica em países desenvolvidos, tem-se verificado um aumento do número de casos, principalmente entre viajantes provenientes de áreas endêmicas, imigrantes, pessoas institucionalizadas (idosos, crianças, oligofrênicos), portadores do HIV e homens que têm sexo com homens. ${ }^{1,10}$

Estão identificadas pelo menos oito amebas (E. histolytica, E. dispar, E. moshkovskii, E. coli, E. hartmanni, E. polecki, lodamoeba bütschliie Endolimax nana) que vivem no lúmen intestinal do ser humano, sendo que todas elas, com exceção da E. histolytica, são consideradas organismos comensais (não patogênicos e não invasivos)..$^{11,12}$

O ciclo biológico deste parasita é monoxênico, necessitando apenas de um hospedeiro para completar o ciclo (Figura 1). Apresenta quatro estádios evolutivos: quisto (forma infecciosa e não móvel), trofozoíto (forma invasiva e móvel), pré-quisto e metaquisto, sendo as duas últimas formas intermédias. ${ }^{12}$

Um desequilíbrio na homeostasia do hospedeiro é o responsável pelo início da infecção, sendo pior o prognóstico da doença em crianças (principalmente neonatos), grávidas e puérperas, doentes oncológicos, pacientes sob corticoterapia, com abuso crônico de álcool ou mal-nutridos. ${ }^{7}$ 


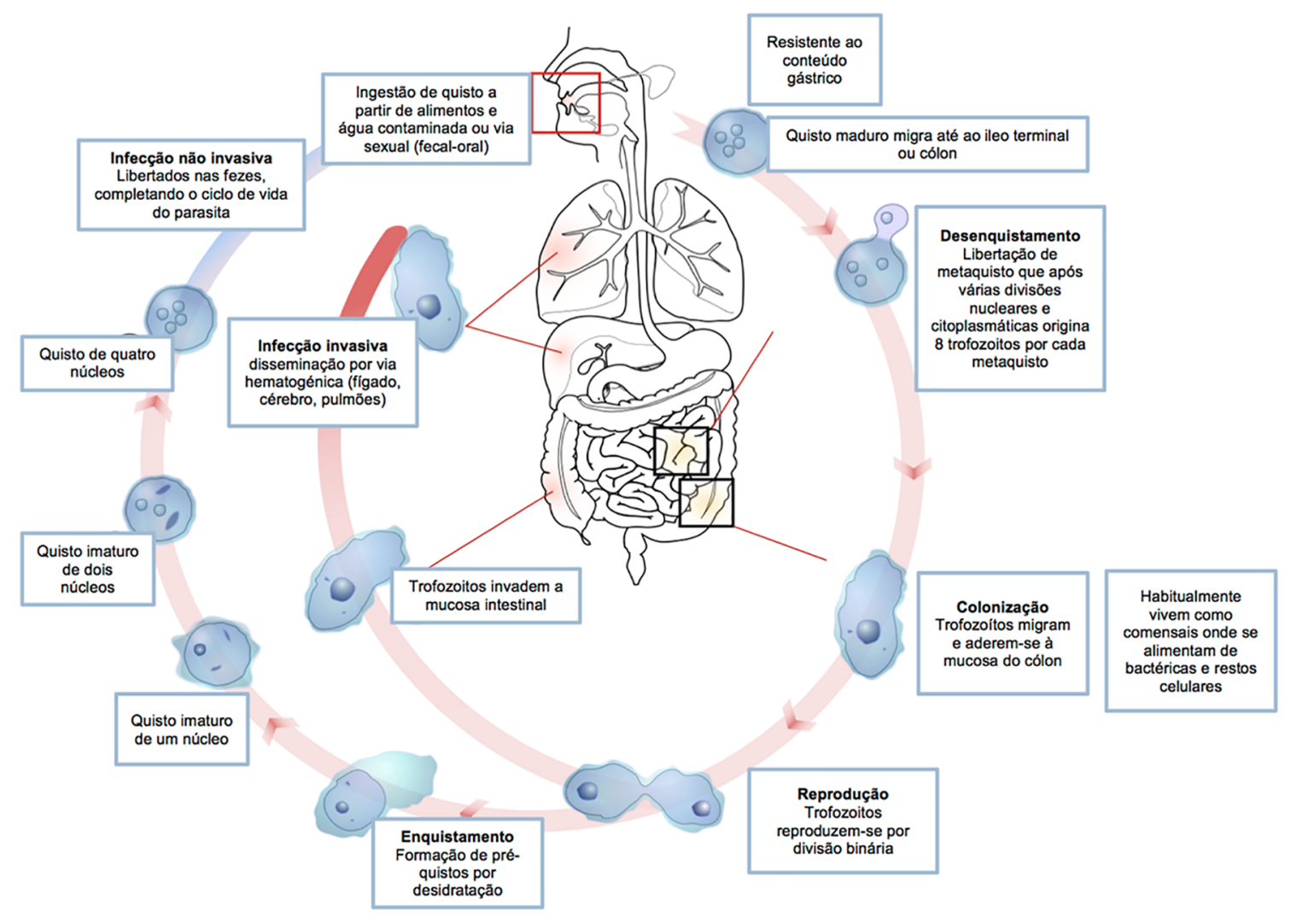

Figura 1. Ciclo biológico e patogênico da Entamoeba histolytica (adaptado de Villarreal' ${ }^{13}$ ).

Apesar da infecção assintomática ter igual prevalência entre os sexos, a doença invasiva é mais comum no sexo masculino. A razão para esta disparidade pode ser atribuída a efeitos hormonais, uma vez que, por exemplo, o risco de desenvolver abcesso hepático aumenta durante o período pós-menopáusico na mulher. ${ }^{14}$

As manifestações clínicas podem incluir diarreia ou doença extraintestinal (abcesso hepático ou manifestações pulmonares, cardíacas ou cerebrais, que são mais raras), embora em $90 \%$ dos casos a infecção seja assintomática, perpetuando o ciclo natural do parasita através da excreção fecal de quistos. A nível mundial, cerca de 50 milhões de pessoas desenvolvem colite ou doença extraintestinal. ${ }^{12,15}$

O diagnóstico diferencial varia de acordo com a apresentação clínica do quadro, incluindo outras causas de diarreia, nomeadamente causas infecciosas de etiologia bacteriana (Shigella, Escherichia coli, Salmonella, Campylobacter, Clostridium difficile e determinadas espécies de Vibrio) e causas não infecciosas como DII e doença intestinal isquêmica. O diagnóstico diferencial é realizado com base em exames culturais ou estudos moleculares. ${ }^{3}$

Numa reduzida percentagem de casos, a amebíase intestinal pode apresentar-se como uma síndrome de diarreia crônica, com perda de peso e dor abdominal sem disenteria, com anos de evolução que mimetiza uma DII, dificultando o correto diagnóstico. ${ }^{16}$

A infecção por E. histolytica não é uma causa frequente de diarreia do viajante, principalmente se permanecer menos de um mês em áreas endêmicas. ${ }^{16}$ 
Apesar do exame parasitológico de fezes não ser o mais específico e sensível para um correto diagnóstico, é um exame de fácil acesso e de baixo custo, realizado em qualquer laboratório e coparticipado pelo Serviço Nacional de Saúde português. Quando este é requisitado, o utente deve fazer a recolha de pelo menos três amostras de fezes em dias alternados devido à eliminação intermitente dos parasitas (aumenta a sensibilidade de $33-50 \%$ para $85-95 \%$ comparado a apenas uma amostra). ${ }^{7}$ Por outro lado, a observação microscópica quando realizada por um patologista experiente facilita a diferenciação morfológica de outras amebas intestinais e artefatos. ${ }^{17}$

O tratamento deve incluir duas classes de fármacos: um antiparasitário (como o metronidazol) seguido de um amebicida intraluminal (como a paromomicina). ${ }^{3,7,16,18}$

O metronidazol, quando usado em formulação oral, é bem absorvido e como não permanece tempo suficiente no lúmen intestinal para erradicar a amebíase (eliminação de quistos) não deve ser usado em monoterapia. ${ }^{19}$

Não existe registro de resistência dos trofozoítos a este fármaco. O paciente apresenta melhoria clínica 72 horas após o início da terapêutica. Os principais efeitos adversos são gastrointestinais: anorexia, náuseas, vômitos, diarreia, desconforto abdominal, parageusia e efeito dissulfiram. ${ }^{3}$

A paromomicina é um aminoglicosídeo não absorvido no tubo digestivo e com atividade intraluminal essencialmente contra os quistos, promovendo assim a eliminação dos mesmos e consequente prevenção da recidiva. ${ }^{18}$

Não é comercializado em Portugal, havendo a necessidade de ser importado, e o seu uso é exclusivo de ambiente hospitalar. Dado que a diarreia é um efeito secundário frequente da paromomicina, esta não deve ser administrada juntamente com o metronidazol, uma vez que dificulta a percepção da resposta à terapêutica inicial. ${ }^{3}$

É importante para o Médico de Família equacionar esta etiologia na investigação de doentes com diarreia, para um correto e atempado diagnóstico e tratamento.

Deve insistir-se na instituição de medidas de higiene em viajantes para áreas endêmicas, como comer fruta descascada, ingestão de água engarrafada e alimentos cozidos. Devem ser também discutidos os riscos de práticas sexuais que originem contato fecal-oral. ${ }^{3}$

Por ser facilmente transmissível, os parceiros sexuais dos últimos 3 a 4 meses antes do início dos sintomas, os membros da família e os contatos próximos devem ser testados e posteriormente tratados se colonizados. ${ }^{20}$

Deste modo, torna-se uma prioridade investir na prevenção, quebrar a cadeia de transmissão e evitar, à semelhança do que ocorre em outros países, um grave problema de saúde pública.

A não coparticipação pelo Serviço Nacional de Saúde português do teste serológico do antígeno torna este exame pouco acessível à população com carências econômicas. A alternativa consiste na realização do exame parasitológico de fezes que, apesar de menos sensível e específico, acarreta um custo suportável por estes pacientes. Apesar disto conduzir a um sobrediagnóstico, pela dificuldade de diferenciação de parasitas por este método, podemos assumir que deste modo reduzimos a morbimortalidade associada à afecção quando esta se encontra presente. 
Dado que a paromomicina não se encontra disponível a nível dos cuidados de saúde primários, os pacientes necessitam ser referenciados à consulta hospitalar para realização da terapêutica, o que diminui os contatos posteriores com o Médico de Família e interfere com o seguimento da afecção. Os tempos de espera no agendamento de consultas nos cuidados de saúde secundários diminuem a acessibilidade e originam um aumento da janela de contágio, podendo aumentar o número de contaminações.

Os dois fármacos utilizados têm alguns efeitos adversos frequentes, conduzindo ao não cumprimento terapêutico. Deveria ser feito um acompanhamento regular e a longo prazo para garantir a adesão ao tratamento e a consequente erradicação do agente, assim como vigiar o aparecimento de novos sintomas que exijam mais investigação. Não se encontra descrita em nenhuma das referências bibliográficas consultadas a necessidade de realização de testes de confirmação da eficácia da erradicação do parasita após terapêutica, sendo dedutível que esta foi eficaz se o paciente se mantiver assintomático.

\section{Conflito de interesses}

Declaram não haver.

\section{Contribuição dos autores}

Concepção e delineamento do artigo: Castro AA, Bacalhau F, Silva FF, Avillez C, Batalheiro J. Aquisição e análise formal da literatura: Castro AA, Bacalhau F, Batalheiro J. Redação preliminar: Castro AA, Bacalhau F, Silva FF, Avillez C, Batalheiro J. Revisão crítica da versão preliminar: Castro AA, Bacalhau F, Silva FF, Avillez C, Batalheiro J. Edição da versão definitiva: Castro AA, Bacalhau F.

Todos os autores aprovaram a versão final e concordaram com prestar contas sobre todos os aspectos do trabalho.

\section{Referências}

1. Fine KD, Schiller LR. AGA technical review on the evaluation and management of chronic diarrhea. Gastroenterology. 1999;116(6):1464-86.

2. Camilleri M, Sellin JH, Barrett KE. Pathophysiology, Evaluation, and Management of Chronic Watery Diarrhea. Gastroenterology. 2017;152(3):515-532.e2.

3. Shirley DT, Farr L, Watanabe K, Moonah S. A Review of the Global Burden, New Diagnostics, and Current Therapeutics for Amebiasis. Open Forum Infect Dis. 2018;5(7):ofy161.

4. Fotedar R, Stark D, Beebe N, Marriott D, Ellis J, Harkness J. Laboratory diagnostic techniques for Entamoeba species. Clin Microbiol Rev. 2007;20(3):511-32. https://doi.org/10.1128/CMR.00004-07

5. Pineda E, Perdomo D. Entamoeba histolytica under Oxidative Stress: What Countermeasure Mechanisms Are in Place? Cells. 2017;6(4). pii:E44.

6. Marques FC, Sanches B, Guerreiro A, Nunes F, Azeredo P. Abcesso hepático amebiano em idade pediátrica - um caminho do intestino ao fígado. GE Port J Gastroenterol. 2014;21(5):208-11. https://doi.org/10.1016/j.jpg.2014.06.004

7. Dhawan VK. Amebiasis. 2018. [acesso 2018 Nov 7]. Disponível em: https://emedicine.medscape.com/article/212029-overview\#a2

8. Quintela C, Saiote J, Bettencourt MJ, Marques AD. Rectorragias como forma de apresentação de amebíase. Rev Port Coloproct. 2010;7(3):136-9. 
9. Santos RV, Nunes Jda S, Camargo JA, Rocha EM, Fontes G, Camargo LM. High occurrence of Entamoeba histolytica in the municipalities of Ariquemes and Monte Negro, State of Rondônia, Western Amazonia, Brazil. Rev Inst Med Trop Sao Paulo. 2013;55(3):193-6. https://doi.org/10.1590/S0036-46652013000300010

10. LoYC, Ji DD, Hung CC. Prevalent and incident HIV diagnoses among Entamoeba histolytica-infected adult males: a changing epidemiology associated with sexual transmission--Taiwan, 2006-2013. PLoS Negl Trop Dis. 2014;8(10):e3222.

11. Hooshyar H, Rostamkhani P, Rezaian M. Molecular epidemiology of human intestinal amoebas in Iran. Iran J Public Health. 2012;41(9):10-7.

12. Tanyuksel M, Petri WA Jr. Laboratory diagnosis of amebiasis. Clin Microbiol Rev.2003;16(4):713-29. https://doi.org/10.1128/CMR.16.4.713729.2003

13. Villarreal MR. File:Entamoeba histolytica life cycle-en.svg. Wikimedia Commons. 2008. [acesso 2018 Nov 6]. Disponível em: https://commons.m.wikimedia.org/wiki/File:Entamoeba_histolytica_life_cycle-en.svg

14. Samie A, Obi LC, Bessong PO, Stroup S, Houpt E, Guerrant RL. Prevalence and species distribution of E. Histolytica and E. Dispar in the Venda region, Limpopo, South Africa. Am J Trop Med Hyg. 2006;75(3):565-71. https://doi.org/10.4269/ajtmh.2006.75.565

15. Parija SC, Mandal J, Ponnambath DK. Laboratory methods of identification of Entamoeba histolytica and its differentiation from look-alike Entamoeba spp. Trop Parasitol. 2014;4(2):90-5. https://doi.org/10.4103/2229-5070.138535

16. Addib O, Ziglam H, Conlong P. Invasive amoebiasis complicating inflammatory bowel disease. Libyan J Med. 2007;2(4):214-5. https://doi.org/10.4176/070905

17. Rayan HZ. Microscopic overdiagnosis of intestinal amoebiasis. Egypt Soc Parasitol. 2005;35(3):941-51.

18. Hung CC, Chang SY, Ji DD. Entamoeba histolytica infection in men who have sex with men. Lancet Infect Dis. 2012;12(9):729-36. https://doi.org/10.1016/S1473-3099(12)70147-0

19. Pickering LK. Amebiasis. In: Pickering LK, Baker CJ, Kimberlin DW, eds; AAP Committee on Infectious Diseases. 2012 Red Book: Report of the Committee on Infectious Diseases. 29 ed. Elk Grove Village: American Academy of Pediatrics; 2012. p. 222-5.

20. Abdolrasouli A, McMillan A, Ackers JP. Sexual transmission of intestinal parasites in men who have sex with men. Sex Health. 2009;6(3):185-94. https://doi.org/10.1071/SH08084 